Cite this: RSC Adv., 2014, 4, 1302

Received 14th September 2013 Accepted 10th October 2013

DOI: $10.1039 / \mathrm{c} 3 \mathrm{ra} 45120 \mathrm{~h}$

www.rsc.org/advances

\section{Dual functionality of conjugated polymer nanoparticles as an anticancer drug carrier and a fluorescent probe for cell imaging $\dagger$}

\author{
Ö. Gezici, ${ }^{a}$ I. Durmaz, ${ }^{b}$ E. Bilget Güven, ${ }^{\text {b }}$ Ö. Ünal, ${ }^{a}$ A. Özgün, ${ }^{c}$ R. Cetin-Atalay ${ }^{b}$ \\ and D. Tuncel ${ }^{\star a c}$
}

Multifunctional nanoparticles based on a green emitting, hydrophobic conjugated polymer, poly[(9,9-bis \{propeny\}fluorenyl-2,7-diyl)-co-(1,4-benzo-\{2,1,3\}-thiodiazole)] (PPFBT), that acts both as a fluorescent reporter and a matrix to accommodate an anti-cancer compound, camptothecin (CPT), were prepared, characterized and their potential as a fluorescent probe for cell imaging and as a drug delivery vehicle were evaluated via in vitro cell assays. The cell viability of human hepatocellular carcinoma cell line (Huh7) was investigated in the absence and presence of CPT with sulforhodamine B (SRB) and real-time cell electronic sensing (RT-CES) cytotoxicity assays.

\section{Introduction}

Nanoparticulate anti-cancer drug carrying systems offer many advantages over conventional chemotherapy. ${ }^{\mathbf{1 , 2}}$ In the latter treatment, the drugs may not approach the target easily or be expelled from the body in a very short time and, as a result, the treatment may require the usage of higher doses of the drugs; in turn, this may cause unwanted side effects. On the other hand, the former has the potential to enable the preferential delivery of drugs to tumors due to the enhanced permeability and retention (EPR) effect, in which the vasculature in tumors is leaky to certain sizes of molecules (e.g. liposomes, nanoparticles and macromolecular drugs) which allows these molecules to accumulate in tumor tissues more than in normal tissues. ${ }^{3,4}$ Various nanostructured-materials in different geometries have been designed and synthesized from inorganic nanoparticles, polymers, lipids and dendrimers to be used as contrast agents, therapeutics, and delivery vehicles..$^{5-11}$ For biomedical applications, nanoparticles smaller than $100 \mathrm{~nm}$ in diameter have been suggested to be ideal because of their favorable bio-distribution

\footnotetext{
${ }^{a}$ Department of Chemistry, Bilkent University, 06800 Ankara, Turkey. E-mail: dtuncel@fen.bilkent.edu.tr

${ }^{b}$ Department of Molecular Biology and Genetics, Bilkent University, 06800 Ankara, Turkey

'Institute of Material Science and Nanotechnology, Bilkent University, 06800 Ankara, Turkey.E-mail: dtuncel@fen.bilkent.edu.tr

$\dagger$ Electronic supplementary information (ESI) available: ${ }^{1} \mathrm{NMR},{ }^{13} \mathrm{C}-\mathrm{NMR}$ and ESI-MS spectra of 2,7-dibromo-9,9-bis-(propenyl)-9H-fluorene, DLS histograms of CPNs at different concentrations of polymer solutions, UV-vis spectra of CPT, the calibration curve, UV-vis and fluorescence spectra of CPT, CPNs and CPT-loaded CPNs and UV-vis spectra of the dialysates obtained from the loading experiments. See DOI: 10.1039/c3ra45120h
}

and excretion/accumulation behavior compared to their smaller counterparts. $^{7-9}$

Lately, a new class of water-dispersible nanoparticles based on conjugated polymers (CPNs) have attracted significant attention. ${ }^{\mathbf{1 2 - 1 4}}$ They exhibit low cytotoxicity, significant photostability, and possess high fluorescent quantum yields and molar absorptivity. Moreover, they can be easily synthesized with desired emission wavelengths and functionalities from a number of different polymers. ${ }^{15-19}$ These features make them very attractive for photonics ${ }^{20-22}$ and biomedical applications. ${ }^{23-32}$ Cellular uptake and cytotoxicity studies of CPNs based on various conjugated polymers have been reported, and these studies have clearly demonstrated that CPNs were taken up efficiently by the cells through endocytosis even in a very short incubation time. ${ }^{33}$ Nanoparticles have also been prepared for drug delivery through the electrostatic assembly of a cationic polyfluorene based conjugated polymer with doxorubicin conjugated anionic poly(L-glutamic acid). ${ }^{34}$ However, to the best of our knowledge, there are no reports on the facile synthesis of drug-loaded conjugated polymer nanoparticles through a reprecipitation method using only one type of polymer, and their dual use for drug delivery and imaging.

Here, we report on multifunctional CPNs which can be used for drug delivery and cell imaging. First, nanoparticles with an average diameter of about $25 \mathrm{~nm}$ and based on a green emitting, hydrophobic conjugated polymer, poly[(9,9-bis\{propeny\}fluorenyl-2,7-diyl)-co-(1,4-benzo-\{2,1,3\}-thiodiazole)] (PPFBT) were prepared, characterized and their suitability as a fluorescent marker for cell imaging was evaluated by in vitro cell assays. Then, drug loaded nanoparticles in which PPFBT acts both as a fluorescent reporter and a matrix to encapsulate an anticancer drug, camptothecin (CPT), were synthesized through a facile, single step reprecipitation method. CPT is a quinoline 
alkaloid-based chemotherapy drug which accomplishes its anticancer activity by inhibiting the DNA topoisomerase-I activity. ${ }^{35,36}$ However, one of the drawbacks which prevents its wide clinical use is its poor water solubility. Although watersoluble analogues have been synthesized and tested for their anticancer activity, they exhibited adverse side effects due to the solubilizing groups attached to the CPT backbone. Therefore, to address this solubility problem, it is highly desirable, and one of the objectives of this work, to achieve this through encapsulation.

\section{Experimental section}

All reagents were purchased from Sigma-Aldrich Chemical Co. and were used as received. Morphological characterization was achieved by atomic force microscopy-PSIA (AFM, XE-100E) and transmission electron microscopy (TEM, FEI Tecnai G2 F30). Negative staining with phosphotungstic acid was applied in order to obtain TEM images. The size of the nanoparticles was measured by dynamic light scattering (DLS, Zetasizer Nano-ZS). Measurements were carried out at $633 \mathrm{~nm}$ and the laser, as the light source, was used at room temperature. The time-dependent autocorrelation function of the scattered light intensity was measured at an angle of $90^{\circ}$. The average particle diameter was calculated by the Marquardt method. The DLS measurements were usually repeated at least three times and the average values are reported. For the optical characterization, a UV-vis spectrophotometer (Cary UV-vis) and a fluorescence spectrophotometer (Cary Eclipse Fluorescent spectrophotometer) equipped with a xenon-lamp as the excitation source were used. For the structural characterization, nuclear magnetic resonance (NMR, a Bruker Avance III 400 for ${ }^{1} \mathrm{H}$ and a $100 \mathrm{MHz}$ spectrometer for ${ }^{13} \mathrm{C}$ ) and FT-IR (Bruker TENSOR 27) spectra were obtained. Each sample was dropped onto a silicon wafer. The data were recorded at $25{ }^{\circ} \mathrm{C}$, in the spectral range of 4000-400 $\mathrm{cm}^{-1}$, by accumulation of 256 scans with a resolution of $4 \mathrm{~cm}^{-1}$. Autoclaved $\mathrm{dd}_{2} \mathrm{O}$ was used to prepare the nanoparticles. The molecular weight of the polymers was determined using gel permeation chromatography (GPC, Agilent 1200) with THF as the eluent and polystyrene as the standard.

\section{Synthesis of 2,7-dibromo-9,9-bis-(propenyl)-9H-fluorene}

2,7-Dibromofluorene (3.0 g, $9.25 \mathrm{mmol})$ and tetrabutylammoniumbromide (TBAB) (0.6 g, $1.85 \mathrm{mmol}$ ) were dried under vacuum for $30 \mathrm{~min}$. Degassed DMSO $(15 \mathrm{~mL}), 50 \%(\mathrm{w} / \mathrm{w}) \mathrm{NaOH}$ $(15 \mathrm{~mL})$, allylbromide $(16 \mathrm{~mL}, 90 \mathrm{mmol})$ were added into the mixture respectively and stirred under argon gas for two hours at room temperature. After two hours, $t$-butyl methyl ether $(125 \mathrm{~mL})$ and deionized water $(50 \mathrm{~mL})$ were added to the mixture and stirred $15 \mathrm{~min}$. The organic layer was separated and subsequently washed with deionized water $(50 \mathrm{~mL}), 2 \mathrm{~N} \mathrm{HCl}$ $(50 \mathrm{~mL})$, a brine solution $(50 \mathrm{~mL})$ and deionized water $(50 \mathrm{~mL})$, respectively. After extraction, $t$-butyl methyl ether was evaporated in a rotary evaporator and the monomer was obtained. For the purification of the product, silica-packed column chromatography was used and cyclohexane was used as the eluent.
The solid was further purified by dissolving it in $\mathrm{CHCl}_{3}$ and recrystallizing it with cold methanol. Colorless crystals were collected and dried under vacuum (3.3 g, 89\%).

${ }^{1} \mathrm{H}-\mathrm{NMR}\left(400 \mathrm{MHz}, \mathrm{CDCl}_{3}\right): \delta 7.52(\mathrm{~m}, 6 \mathrm{H}, \mathrm{Ar}-\mathrm{H}), 5.21$ $\left(\mathrm{m}, 2 \mathrm{H},-\mathrm{CH}=\mathrm{CH}_{2}\right), 4.89\left(\mathrm{~m}, 4 \mathrm{H},-\mathrm{CH}=\mathrm{CH}_{2}\right), 2.68\left(\mathrm{t}, 4 \mathrm{H},-\mathrm{CH}_{2}-\right.$, $\left.{ }^{3} J=4 \mathrm{~Hz}\right) .{ }^{13} \mathrm{C}-\mathrm{NMR}\left(100 \mathrm{MHz}, \mathrm{CDCl}_{3}\right): \delta 43.2,54.7,118.5,121.2$, 127.0, 130.5, 132.6, 138.7, 151.1. Elemental analysis: calc.: C, 56.47; H, 3.99; found: C, 56.12; H, 4.08\%. ESI-MS: $m / z 401.8[\mathrm{M}]^{+}$.

\section{Synthesis of poly[(9,9-bis\{propeny\}fluorenyl-2,7-diyl)-co-(1,4-} benzo- $\{2,1,3\}$-thiodiazole)] (PPFBT)

2,1,3-Benzothiadiazole-4,7-bis (boronic acid pinocol ester) (573 mg, $1.47 \mathrm{mmol}$ ), 2,7-dibromo-9,9-bis-(propenyl)-9H-fluorene (500 mg, $1.47 \mathrm{mmol}$ ) and $\mathrm{K}_{2} \mathrm{CO}_{3}(2.04 \mathrm{~g}, 14.7 \mathrm{mmol}$ ) were dried under vacuum about $30 \mathrm{~min}$. First, degassed solvents, THF $(10 \mathrm{~mL})$, water $(10 \mathrm{~mL})$ and toluene $(10 \mathrm{~mL})$, were added under argon gas and then the catalyst tetrakis (triphenylphosphine) palladium $\left(\mathrm{Pd}\left(\mathrm{PPh}_{3}\right)_{4}\right)(20 \mathrm{mg}, 0.018 \mathrm{mmol})$ was added quickly. After stirring the mixture for $3 \mathrm{~h}$ under argon at 80$90{ }^{\circ} \mathrm{C}$, the phase transfer catalyst, tetra- $n$-butylammonium bromide (TBAB) (30 mg) was added. The stirring was continued for another $48 \mathrm{~h}$ at $80-90{ }^{\circ} \mathrm{C}$ to complete the polymerization reaction. The mixture was evaporated under vacuum to obtain a solid residue that was then suspended in water. The water insoluble particles were collected by filtration and dissolved in THF $(20 \mathrm{~mL})$, followed by the addition of cold methanol $(200 \mathrm{~mL})$. The precipitate was collected by filtration and dried under vacuum for $5 \mathrm{~h}$ (646 mg, 60\%).

${ }^{1} \mathrm{H}$ NMR (400 MHz, $\left.\mathrm{CDCl}_{3}, \delta\right): 8.15(\mathrm{~m}, 8 \mathrm{H}, \mathrm{Ar}-\mathrm{H}), 5.60(\mathrm{~m}$, $\left.2 \mathrm{H},-\mathrm{CH}=\mathrm{CH}_{2}\right), 5.0\left(\mathrm{t}, 4 \mathrm{H},-\mathrm{CH}=\mathrm{CH}_{2}\right), 2.91\left(\mathrm{t}, 4 \mathrm{H},-\mathrm{CH}=\mathrm{CH}_{2}\right)$. IR (KBr, pellet, $\left.v_{\max }\left(\mathrm{cm}^{-1}\right)\right): 3074(-\mathrm{CH}, \mathrm{w}), 2918(-\mathrm{CH}, \mathrm{s}), 1455$ $(\mathrm{C}=\mathrm{C}-, \mathrm{w})$. GPC: $M_{\mathrm{n}}=4.5 \times 10^{3} \mathrm{~g} \mathrm{~mol}^{-1}, M_{\mathrm{w}}=1.1 \times 10^{4} \mathrm{~g}$ $\mathrm{mol}^{-1}$, PDI $=2.4$ (polystyrene as standard).

\section{Preparation of the nanoparticles}

PPFBT ( $2.0 \mathrm{mg}, 5.26 \times 10^{-3} \mathrm{mmol}$, based on per repeating unit) was dissolved in THF ( $5 \mathrm{~mL})$. The resulting solution was sonicated for $30 \mathrm{~min}$ and then injected rapidly into autoclaved double distilled water $(50 \mathrm{~mL})$. It was stirred under sonication for further $30 \mathrm{~min}$. THF was removed under reduced pressure. The resulting nanoparticle solution was concentrated by evaporating its water under reduced pressure to get a concentration of PPFBT of $0.75 \mathrm{mg} \mathrm{mL}^{-1}\left(1.98 \times 10^{-3} \mathrm{mmol} \mathrm{mL}^{-1}\right)$.

\section{Preparation of drug loaded nanoparticles: determination of drug loading capacity and entrapment efficiency}

Five sets of drug-loaded nanoparticles were prepared with drug to polymer ratios of $1: 0.5(\mathrm{w} / \mathrm{w}), 1: 1(\mathrm{w} / \mathrm{w}), 1: 2(\mathrm{w} / \mathrm{w}), 1: 10$ $(\mathrm{w} / \mathrm{w})$ and $1: 25(\mathrm{w} / \mathrm{w})$.

The following is the typical procedure for the preparation of the drug loaded nanoparticles (drug to polymer ratio: 1 : 25 (w/ w)): PPFBT (2.0 mg, $5.26 \times 10^{-3} \mathrm{mmol}$, based on per repeating unit) and CPT $\left(0.08 \mathrm{mg}, 0.23 \times 10^{-3} \mathrm{mmol}\right)$ were dissolved in THF ( $5 \mathrm{~mL}$ ). The resulting solution was sonicated for $30 \mathrm{~min}$ and then injected rapidly into autoclaved double distilled water $(50 \mathrm{~mL})$. It was stirred under sonication for further $30 \mathrm{~min}$. THF 
was removed under reduced pressure and the CPN dispersion was concentrated to $5 \mathrm{~mL}$ and dialyzed against water using a $14 \mathrm{kDa}$ MWCO regenerated cellulose membrane for $24 \mathrm{~h}$ to remove any remaining free CPT. Tween $20(0.2 \%, \mathrm{v} / \mathrm{v})$ was added to the dialysate to solubilize the free CPT. UV-vis absorbance spectra $\left(\lambda_{\max }=366 \mathrm{~nm}\right)$ of the dialysates were recorded to determine the concentration of CPT. Samples of known concentration of CPT dissolved in water containing Tween 20 $(0.2 \%, v / v)$ were used to obtain a calibration curve of CPT.

\section{In vitro drug-release studies}

$10 \mathrm{mM}$ phosphate buffer saline (PBS) containing $0.2 \%$ Tween 20 was used as the release medium to improve the drug solubility. A $3 \mathrm{~mL}$ aliquot of the drug encapsulated nanoparticle dispersion was mixed with $7 \mathrm{~mL}$ of PBS and transferred into a cellulose tubular membrane with a molecular weight cut-off of $14 \mathrm{kDa}$. A dialysis tube was placed in a beaker containing $100 \mathrm{~mL}$ of PBS and $0.2 \mathrm{wt} \%$ Tween 20 and shaken at $60 \mathrm{RPM}$ and $37{ }^{\circ} \mathrm{C}$ in an incubator. A $1 \mathrm{~mL}$ aliquot was withdrawn from the dialysate at different time intervals during the 110 hours and, at each time, equal amounts of fresh PBS was added to the dialysate beaker to prevent sink conditions. The concentration of CPT in the release medium was measured by using absorption spectrophotometry $\left(\lambda_{\max }=366 \mathrm{~nm}\right)$.

\section{Preparation of cells and culture medium}

Human hepatocellular carcinoma cell line Huh7 was maintained in a Dulbecco's Modified Eagle's Medium (DMEM) (Invitrogen GIBCO) with 10\% fetal bovine serum (FBS) (Invitrogen GIBCO), non-essential amino acids and $1 \%$ penicillin (Biochrome). Huh7 cells were incubated at $37{ }^{\circ} \mathrm{C}$ with $5 \% \mathrm{CO}_{2}$. DMSO (Sigma) was used as the solvent for camptothecin (Calbiochem) at a concentration less than $1 \%$ in the cell culture medium.

\section{Cytotoxicity assays}

Initial screening of the compounds for cytotoxic activity was conducted by using the NCI-60 Sulforhodamine B (SRB) Colorimetric assay. ${ }^{37-39}$ In order to assess the real-time cell analysis (RT-CES, ACEA Biosciences), first a steady impedance value was obtained by adding $50 \mu \mathrm{L}$ of cell culture media to each well of the $96 \times$ e-plate (Roche Applied Sciences). Then, human liver cancer cells (Huh7) were inoculated (2000 cell per well). The attachment, spreading, and proliferation of the cells were monitored every 30 minutes using RT-CA in a cell culture incubator. 24 hours later, as the cells reached their log growth phase, they were treated with various concentrations of the compounds (from $1 \mu \mathrm{M}$ to $0.06 \mu \mathrm{M}$ ). For the control, only DMSO or only $\mathrm{dd}_{2} \mathrm{O}$ was added to the wells. The experiments were conducted in triplicate. The electronic readout (cell-sensor impedance) was displayed at an arbitrary unit called the cell index (CI). The CI value was noted every 10 minutes for the first 24 hours and then every 30 minutes. The cell inhibition rate $(\%)=$ $\left(1-\mathrm{CI}_{\text {treated cells }} / \mathrm{CI}_{\mathrm{DMSO}}\right) \times 100$.

\section{Cell staining and imaging}

Huh7 cells plated on coverslips and treated with CPT, CPT-loaded CPNs, DMSO only and CPNs only for $24 \mathrm{~h}$ and $72 \mathrm{~h}$ were $\mathrm{MeOH}(100 \%$, ice-cold) fixed prior to staining. Then, two drops per mL of medium of ActinRed 555 Ready Probes Reagent (Invitrogen) was added. Following a 30 min dark incubation, cells were washed with PBS and then counter-stained with $1 \mu \mathrm{g}$ $\mathrm{mL}^{-1}$ Hoechst 33258. Coverslips de-stained with ddH2O were mounted on glass slides and examined under a fluorescence microscope (Nikon ECLIPSE 50i).

\section{Results and discussion}

The polymer PPFBT, which contains a propenyl group as a side chain, was synthesized using the Suzuki coupling reaction of 2,7-dibromo-9,9-bis-(propenyl)-9H-fluorene and 1,2,3-benzothiadiazole-4,7-bis(boronic acid pinocol ester) as shown in Scheme 1. The 9,9-position of the fluorene was substituted with the propenyl group because, if necessary, the nanoparticles made from PPFBT could be stabilized through light-induced cross-linking of the double bonds to form a cross-linked shell or targeting groups/biomolecules could be attached to the nanoparticles through thiol-en click chemistry for further applications.

The polymer PPFBT was purified by precipitation of the polymer solution in THF with cold methanol to provide an orange powder in $60 \%$ yield which was characterized by ${ }^{1} \mathrm{H}$-NMR spectroscopy, UV-vis spectroscopy, fluorescence spectroscopy and FT-IR spectroscopy. The ${ }^{1} \mathrm{H}-\mathrm{NMR}$ spectrum of PPFBT is shown in Fig. 1 which confirms the desired structure of the polymer.

Conjugated polymer nanoparticles (CPNs) were prepared by a simple reprecipitation method in which a PPFBT solution in THF

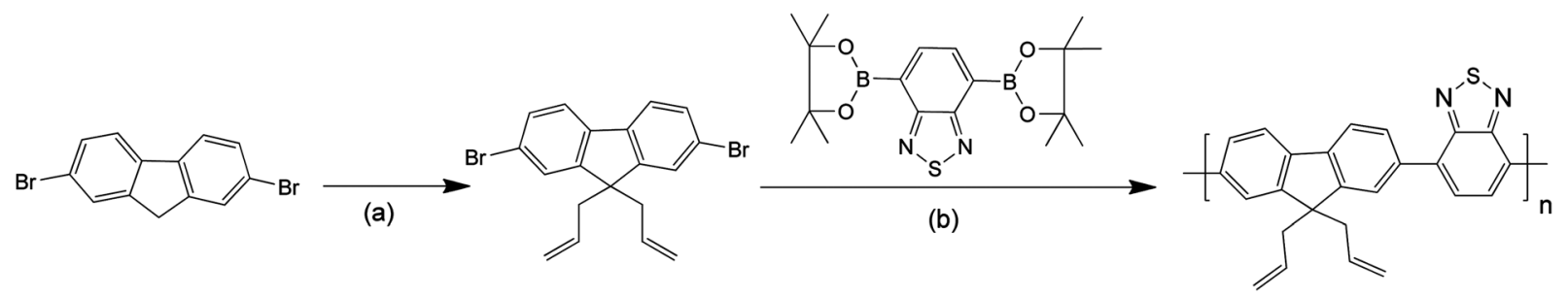

Scheme 1 Synthesis of poly[(9,9-bis\{propeny\}fluorenyl-2,7-diyl)-co-(1,4-benzo-\{2,1,3\}-thiodiazole)] PPFBT. (a) Allylbromide, 50\% NaOH (aq.), DMSO, TBAB, $2 \mathrm{~h}, \mathrm{RT}, 89 \%$, (b) $\mathrm{Pd}\left(\mathrm{PPh}_{3}\right)_{4}, \mathrm{~K}_{2} \mathrm{CO}_{3}, \mathrm{THF}-\mathrm{H}_{2} \mathrm{O}, 80^{\circ} \mathrm{C}, 48 \mathrm{~h}, 60 \%$. 


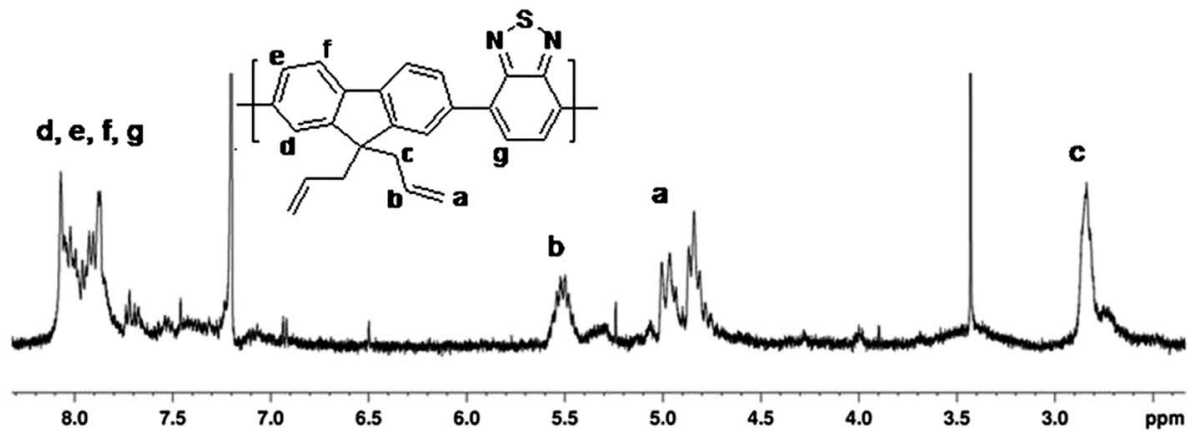

Fig. $1{ }^{1} \mathrm{H}-\mathrm{NMR}\left(400 \mathrm{MHz}, \mathrm{CDCl}_{3}, 25^{\circ} \mathrm{C}\right)$ spectrum of PPFBT.

was injected into a large excess of water under sonication. After removal of the THF under reduced pressure, stable CPNs were obtained. We should also mention that the concentration of the polymer solution used in the nanoparticle synthesis directly affects the size of the nanoparticles as it has also been reported in the literature previously. ${ }^{\mathbf{1 6 - 1 8}}$ We have prepared nanoparticles with average diameters of $25 \mathrm{~nm}, 76 \mathrm{~nm}, 103 \mathrm{~nm}$ and $155 \mathrm{~nm}$ by varying the concentration of the polymer solution (see ESI, Fig. $\mathbf{S} 4, \dagger$ for their DLS histograms). In this study, we opted to use the nanoparticles with the average diameter of $25 \mathrm{~nm}$.

The optical properties of the nanoparticles were investigated by UV-vis and fluorescence spectroscopy and compared to the polymer in THF and in solid state (Fig. 2).

Maximum absorption peaks were observed at 317 and 447 $\mathrm{nm}$ for the polymer in THF; these are almost the same for the CPNs in water and approximately 10 and $25 \mathrm{~nm}$ red shifted for the film of polymer. However, when CPNs were excited at 447 $\mathrm{nm}$, a green-yellow emission band at $550 \mathrm{~nm}$ was observed, which was $13 \mathrm{~nm}$ red shifted compared to the emission band of the polymer in THF. If the emission wavelength of CPNs is compared to the emission wavelength of the polymer film, it can be seen that there is only $8 \mathrm{~nm}$ of difference between them (550 $\mathrm{nm}$ for the CPNs water dispersion and $558 \mathrm{~nm}$ for the polymer film) indicating that the optical properties of the nanoparticles resembles those of the polymer's solid state. The quantum

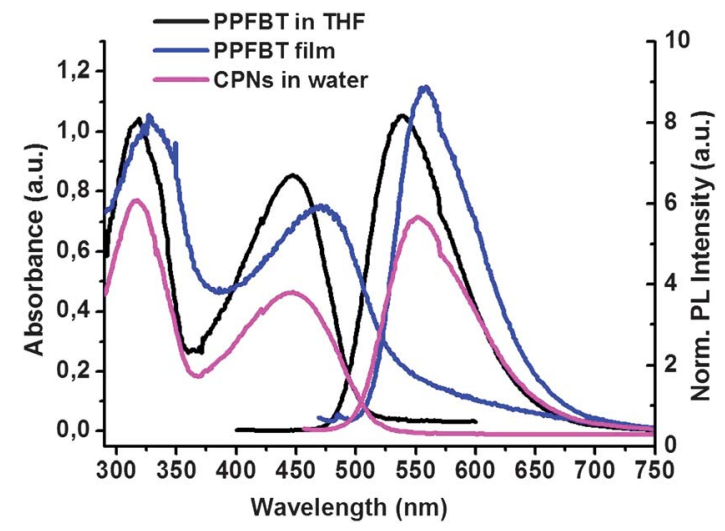

Fig. 2 UV-vis absorption and emission spectra of PPFBT in THF ( $\lambda_{\text {exc. }}=$ $447 \mathrm{~nm})$ and as a film $\left(\lambda_{\text {exc. }}=472 \mathrm{~nm}\right)$, and of a dispersion of the nanoparticles in water $\left(\lambda_{\text {exc. }}=447 \mathrm{~nm}\right)$.

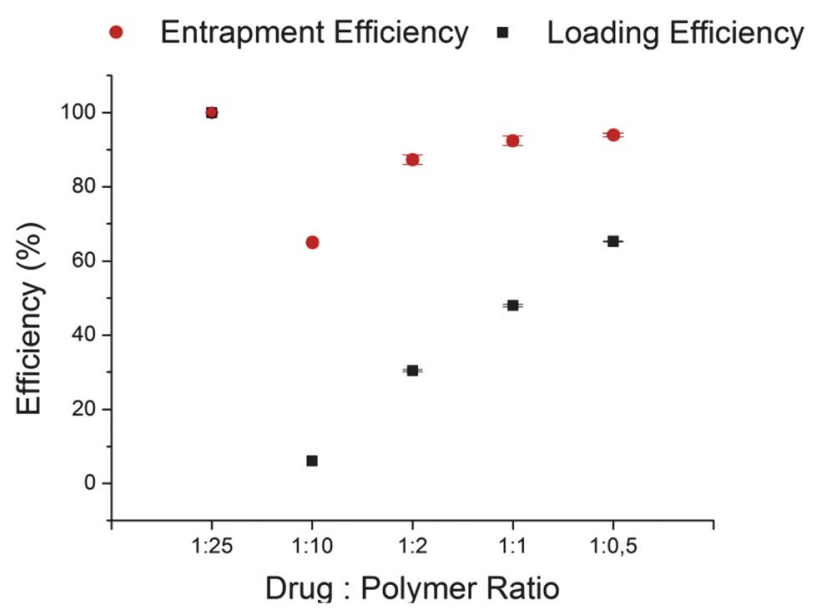

Fig. 3 Entrapment and loading efficiencies of the nanoparticles with various drug to polymer ratios.

yields of PPFBT in THF and the dispersion of CPNs in water were calculated as $70 \%$ and $26 \%$, respectively, using fluorescein dye as the standard. The red shift of the emission maximum for the CPNs compared to the polymer in THF indicates the aggregation of polymer chains upon the nanoparticle formation in water. As a result of this aggregation, the overlap of $\pi$-orbitals increases, followed by $\pi$-electron delocalization across the chains. The lower band gaps, indicated by the red shift, are a sign of this delocalization. Similarly, the red shift in the emission maximum of the polymer in solid state is the result of the tight packing of the polymer chains. ${ }^{17-19,29}$

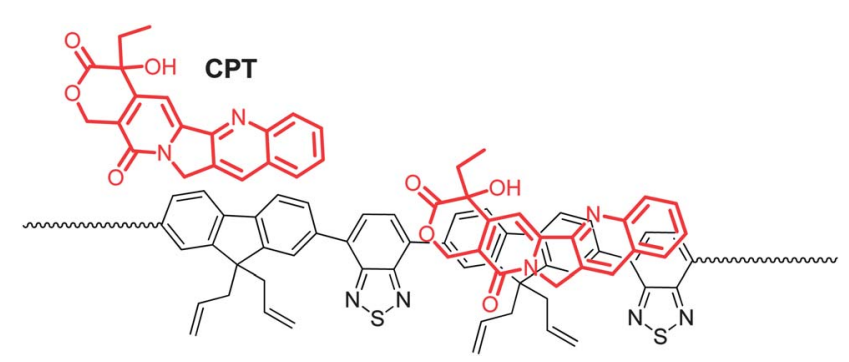

Fig. 4 Schematic representation of the $\pi-\pi$ interactions between the aromatic polymer backbone and the aromatic rings of CPT. 

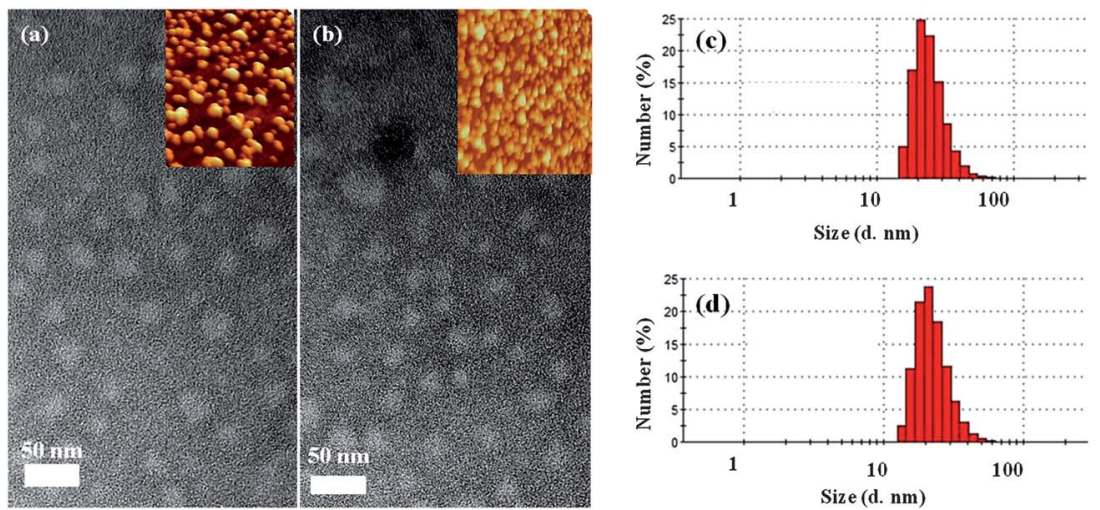

Fig. 5 TEM images of CPNs (a) and CPT-loaded CPNs (b); the insets are their AFM images (scale: $0.5 \times 0.5 \mu \mathrm{m}$ ). Dynamic light scattering histograms of CPNs (c) and CPT-loaded CPNs (d).

Camptothecin loaded CPNs were prepared in a single step synthesis as described in the experimental section. In order to determine the loading and entrapment efficiency of the nanoparticles, ratios of CPT to PPFBT (w/w) $1: 0.5,1: 1,1: 2,1: 10$ and $1: 25$ were used during the nanoparticle preparation. In each case, after the nanoparticle formation, the dispersion was dialyzed against water using a $14 \mathrm{kDa}$ MWCO regenerated cellulose membrane for $24 \mathrm{~h}$ to remove any remaining unencapsulated CPT. The dialysates were analyzed by recording their absorption spectra $\left(\lambda_{\max }=366 \mathrm{~nm}\right)$ (ESI, Fig. S6 $\dagger$ ) and the unencapsulated CPT concentration was calculated from a calibration curve of CPT which was constructed from known concentrations of CPT solutions (ESI, Fig. S5†). The entrapment efficiency (EE) and loading efficiency (LE) were calculated according to the following equations and the results are plotted in Fig. 3.

$$
\begin{gathered}
\mathrm{EE} \%=\text { loaded drug wt/total drug wt } \times 100 \\
\text { LE } \%=\text { loaded drug wt/total system wt } \times 100
\end{gathered}
$$

In Fig. S7 (ESI $\dagger$ ), the UV-vis absorption and the emission spectra of CPT-loaded CPNs, a CPN dispersion in water and CPT in water containing Tween $20(0.2 \%, \mathrm{v} / \mathrm{v})$ are compared. The main driving forces for the encapsulation of CPT by PPFBT to form drug-loaded nanoparticles are probably the hydrophobic

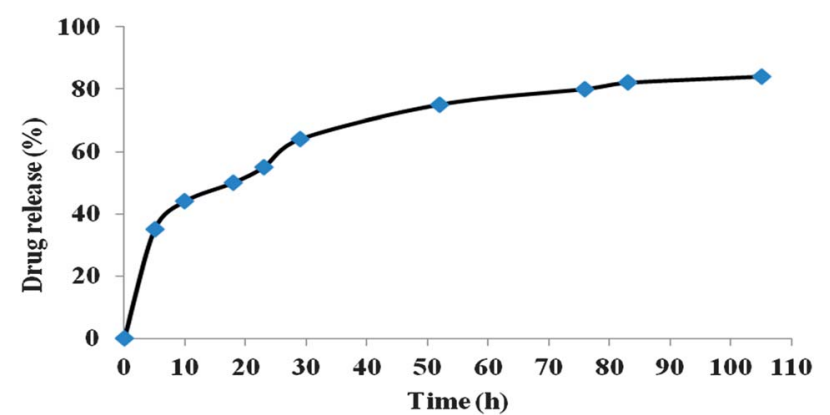

Fig. 6 The time-dependent release profile of CPT from the nanoparticles. effect and the $\pi-\pi$ interactions between the aromatic polymer backbone and the aromatic rings of CPT as shown schematically in Fig. 4.

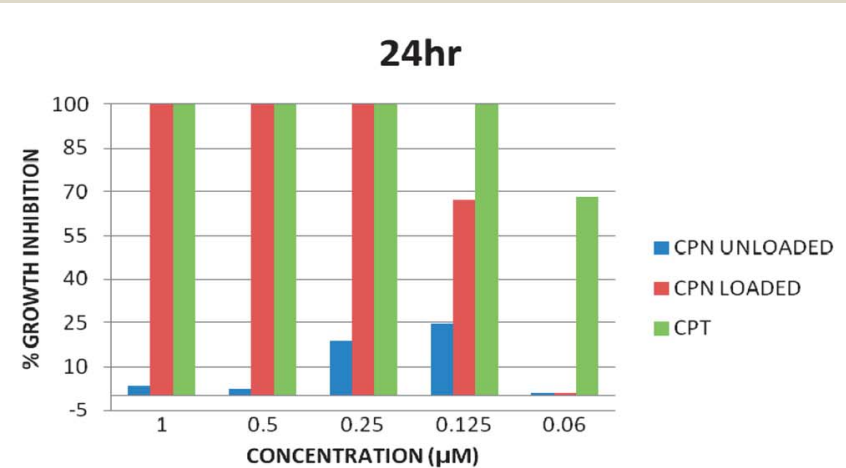

$48 \mathrm{hr}$

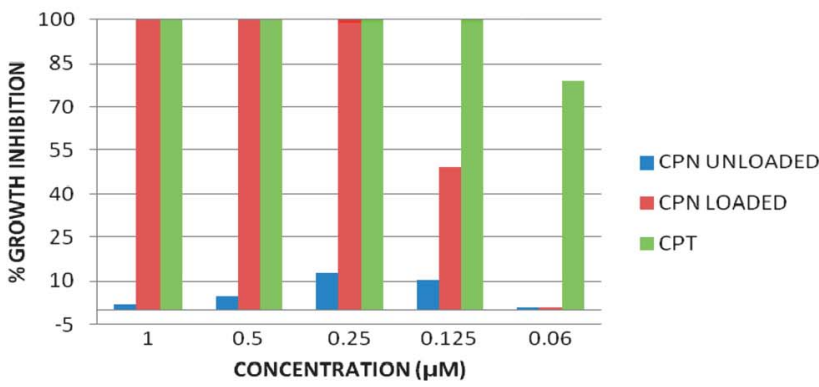

$72 \mathrm{hr}$

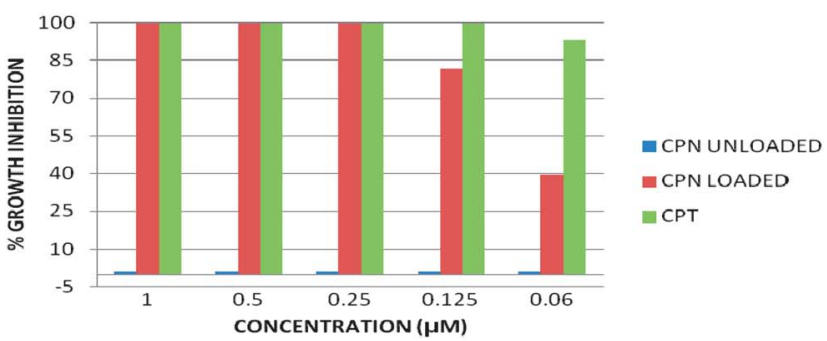

Fig. 7 Real-time growth inhibitory effect of loaded and blank CPNs with camptothecin on the human liver (Huh7) cancer cell line for $24 \mathrm{~h}$, $48 \mathrm{~h}$ and $72 \mathrm{~h}$ incubation periods. The cytotoxicity effects were determined by RT-CES. The experiments were conducted in triplicate. 
The synthesis of blank CPNs and CPT-loaded CPNs was repeated more than three times by keeping the synthetic conditions constant. Their size was determined by dynamic light scattering (DLS) measurements (Fig. 5c and d) and the average of three different DLS measurements was calculated to be $25.50 \pm 0.76 \mathrm{~nm}$ for the CPNs and $24.38 \pm 1.37 \mathrm{~nm}$ for the drug loaded CPNs. The morphology of the CPNs and CPTloaded CPNs was studied by TEM (Fig. 5) and AFM imaging techniques. The zeta potential values were measured as -51.17 \pm 2.16 and $-29.80 \pm 6.52 \mathrm{eV}$ for CPNs and $-40.70 \pm 4.82 \mathrm{eV}$ for CPT-loaded CPNs, which indicate the formation of stable nanoparticle dispersions caused by repulsion between the nanoparticles. As it can be seen from the DLS measurements and TEM images, no significant changes are observed in their diameter, indicating that the structural integrity of the nanoparticles is not affected when they are loaded with drug. The reason could also be attributed to the $\pi-\pi$ interactions between the aromatic conjugated backbone of the polymer chains and the aromatic rings of the CPT molecules, causing a close packing of the drug molecules. Recently, similar results have also been observed by Hennink and co-workers. ${ }^{40}$

The in vitro drug release profile of the CPT-loaded nanoparticles was investigated in PBS ( $\left.\mathrm{pH} 7.4,37^{\circ} \mathrm{C}\right)$ as described in the experimental section, and the release profile of CPT from the nanoparticles is shown in Fig. 6. The time-dependent release profile of CPT from the nanoparticles was measured by the absorption at $366 \mathrm{~nm}$ with UV-vis spectrophotometry. Over the first $18 \mathrm{~h}$, about $50 \%$ of the loaded CPT was released, followed by a sustained release for up to 5 days.

Time and dose dependent in vitro cytotoxicity tests of blank CPNs, CPT-loaded CPNs and free CPT against Huh7 cells were performed by RT-CES and the results are plotted in Fig. 7. In this experimental set-up, free CPT was used as a positive control and DMSO and blank CPNs were used as negative controls to the

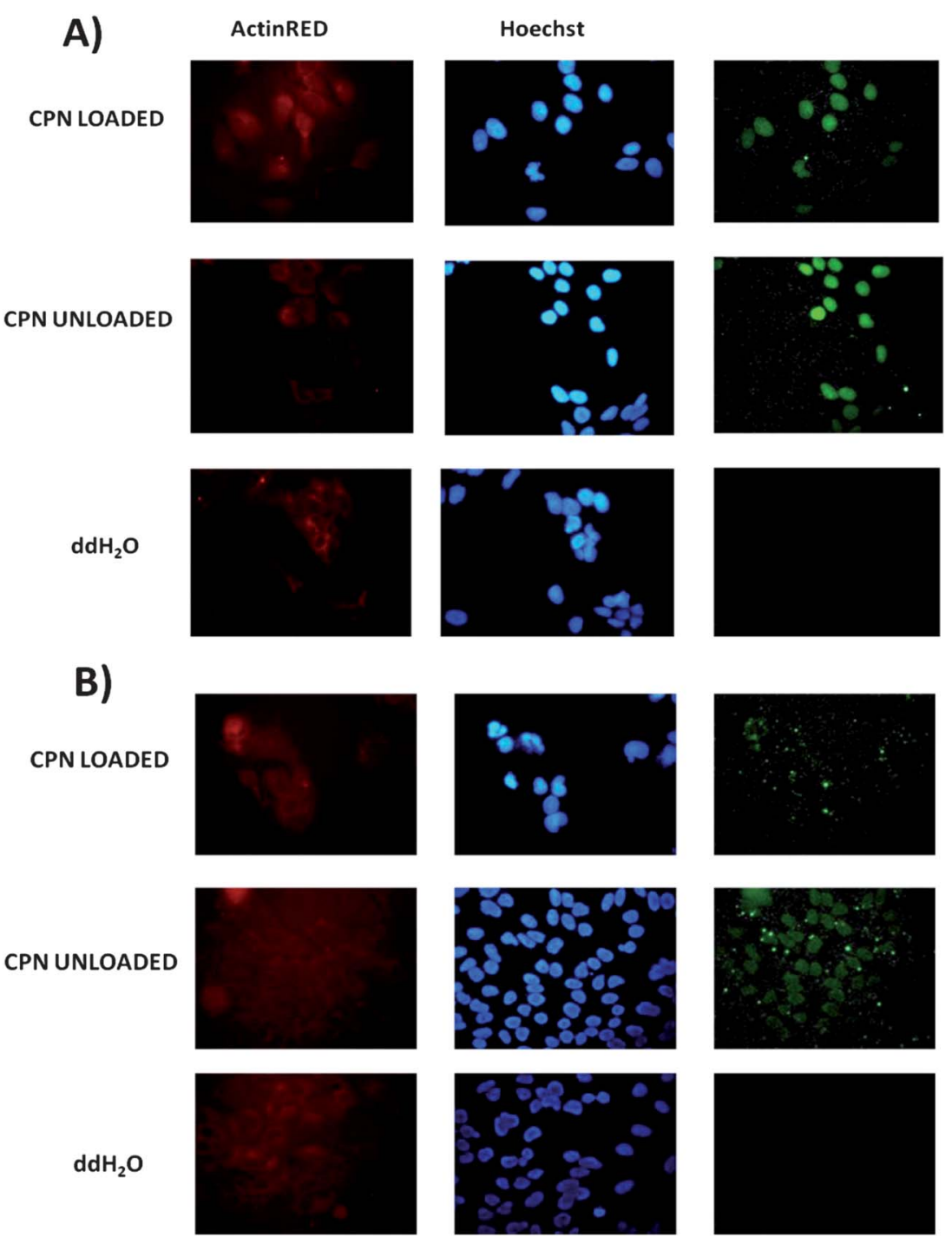

Fig. 8 Fluorescence images of Huh7 cells plated on coverslips and treated with green emitting CPT-loaded CPNs, unloaded-CPNs and dd $\mathrm{H}_{2} \mathrm{O}$ as the control at concentrations of $0.125 \mu \mathrm{M}$ after (A) $24 \mathrm{~h}$ and (B) $72 \mathrm{~h}$ incubations. The blue fluorescence arises from the nuclear stain Hoechst 33258 ( $c$ and d) and the red fluorescence from ActinRed 555 Probes (Invitrogen). Images were acquired with a 20× objective. 
CPT-loaded CPNs. The cytotoxicity assay of the blank CPNs indicates that they are not toxic to the Huh7 cells up to a concentration of $25 \mu \mathrm{M}$. CPT caused almost $100 \%$ growth inhibition at all doses except at $0.06 \mu \mathrm{M}$ (Fig. S9, ESI $\dagger$ ). This behaviour indicates the activation of the necrosis pathway, which is not the preferred death pathway in cancer treatment but apoptosis. Moreover, the small increase in the growth inhibition of the blank CPNs (CPN unloaded) after 12 hours is probably not due to cell death. RT-CES experiments involve using a gold plate and the system relies on electrical impedance cell sensors arrays embedded at the bottom of the plates. Even though there is no cell death, any change in the size of the cells can also be interpreted as growth inhibition. Therefore, the quick increase in the unloaded CPN samples was probably not due to cell death but to a change in the size of the cells caused by the addition of the unloaded CPN solution to the culture media.

CPT-loaded CPNs were analyzed by fluorescence microscopy on Huh7 cells. In Fig. 8 (see also Fig. S8, ESI†), the bright green CPN emission is evidence of an efficient cellular internalization. Especially, at $24 \mathrm{~h}$, the nuclei seem to be densely populated with CPT-loaded CPNs (Fig. 8A). After $72 \mathrm{~h}$, the CPNs leave the cellular nuclei and exit the cellular nuclei in vesicle form (Fig. 8B). No green emission was observed in the $\mathrm{ddH}_{2} \mathrm{O}$ controls as expected due to the lack of CPNs. The red fluorescence indicates the presence of actin cytoskeletons and the blue fluorescence emitted by the Hoechst stain indicates the nuclei.

The high efficacy of this approach can be attributed to a number of factors. Amongst them, the drug-loaded nanoparticles have the potential to avoid multidrug resistance mechanisms (MRMs) when they enter the cells via endocytosis. ${ }^{41}$ MRMs operate through transmembrane drug efflux pumps involving cell-surface proteins such as glycoproteins which can prevent small drugs to enter the cells. CPT is a water insoluble drug molecule which dissolves in organic solvents (e.g. DMSO) or in acidified water. None of them are desirable as DMSO has toxic effects to the cells and CPT molecules are hydrolyzed in acidic aqueous media which, in turn, causes their inhibitory activity to decrease. However, encapsulation provides the CPT molecules with both water solubility and the stability to preserve their full activity.

\section{Conclusions}

In conclusion, we have presented a new and simple approach for the development of multifunctional nanoparticles, which can perform simultaneously drug delivery and cell imaging tasks. In this approach, the water-insoluble drug camptothecin was incorporated into the conjugated polymer nanoparticles with a very high loading efficiency due to favourable non-covalent interactions (e.g. hydrophobic effect and $\pi-\pi$ interactions) between the aromatic backbone of the polymer chains and the drug molecules. The drug-loaded nanoparticles were uniform in size, size distribution and surface charge. The time and dose dependent cytotoxicity assay results indicated that these nanoparticles achieve the delivery of water-insoluble anticancer drugs into cancer cells
(Huh7) in an efficient manner leading to effective growth inhibition and therefore cell death. Furthermore, the long term controlled release of CPT from the CPNs is preferable in clinical research for the increased effectiveness of its cytotoxicity. Noticeably, this new imaging-guided drug delivery system does not require a complicated design and synthetic methodology, as it requires only one type of polymer, which can be synthesized easily, that acts both as a photostable fluorescent probe and a matrix to encapsulate the drug molecules.

\section{Acknowledgements}

We acknowledge TBAG 210T139 and 112T704.

\section{References}

1 (a) K. Y. Choi, G. Liu, S. Lee and X. Chen, Nanoscale, 2012, 4, 330-342; (b) Z. Cheng, A. Al Zaki, J. Z. Hui, V. R. Muzykantov and A. Tsourkas, Science, 2012, 338, 903-910; (c) Z. Yu, R. M. Schmaltz, T. C. Bozeman, R. Paul, M. J. Rishel, K. S. Tsosie and S. M. Hecht, J. Am. Chem. Soc., 2013, 135, 2883-2886.

2 J. Xie, S. Lee, X. Chen and X. Adv, Adv. Drug Delivery Rev., 2010, 62, 1064-1079.

3 V. Mailander and K. Landfester, Biomacromolecules, 2009, 10, 2379-2400.

4 L. Chou, K. Ming and W. C. W. Chan, Chem. Soc. Rev., 2011, 40, 233-245.

5 M. Ferrari, Nat. Rev. Cancer, 2005, 5, 161-171.

6 T. M. Allen and P. R. Cullis, Science, 2004, 303, 1818-1822.

7 J. A. Barreto, W. O’Malley, M. Kubeil, B. Graham, H. Stephan and L. Spiccia, Adv. Mater., 2011, 23, H18-H40.

8 Y. Liu, H. Miyoshi and M. Nakamura, Int. J. Cancer, 2007, 120, 2527-2537.

9 W. J. Stark, Angew. Chem., Int. Ed., 2011, 50, 1242-1258.

10 X. Michalet, F. F. Pinaud, L. A. Bentolila, J. M. Tsay, S. Doose, J. Li, G. Sundaresan, A. M. Wu, S. S. Gambhir and S. Weiss, Science, 2005, 307, 538-544.

11 K. Y. Choi, H. Y. Yoon, J.-H. Kim, S. M. Bae, R.-W. Park, Y. M. Kang, I.-S. Kim, I. C. Kwon, K. Choi and S. Y. Jeong, ACS Nano, 2011, 5, 8591-8599.

12 D. Tuncel and H. V. Demir, Nanoscale, 2010, 2, 484-494.

13 J. Pecher and S. Mecking, Chem. Rev., 2010, 110, 6260-6279.

14 K. Landfester, Angew. Chem., Int. Ed., 2009, 48, 4488-4507.

15 C. Wu, C. Szymanski, Z. Cain and J. McNeill, J. Am. Chem. Soc., 2007, 129, 12904-12905.

16 C. Wu, C. Szymanski and J. McNeill, Langmuir, 2006, 22, 2956-2960.

17 I. O. Ozel, T. Ozel, H. V. Demir and D. Tuncel, Opt. Express, 2010, 18, 670-684.

18 E. J. Park, T. Erdem, V. Ibrahimova, S. Nizamoglu, H. V. Demir and D. Tuncel, ACS Nano, 2011, 5, 2483-2492.

19 V. Ibrahimova, S. Ekiz, O. Gezici and D. Tuncel, Polym. Chem., 2011, 2, 2818-2824.

20 T. Kietzke, D. Nehrer, K. Landfester, R. Montenegro, R. Güntner and U. Scherf, Nat. Mater., 2003, 2, 408-412. 
21 T. Kietzke, D. Nehrer, M. Kumke, R. Montenegro, K. Landfester and U. Scherf, Macromolecules, 2004, 37, 4882-4890.

22 E. Fisslthaler, A. Blümel, K. Landfester, U. Scherf and E. J. W. List, Soft Matter, 2008, 4, 2448-2453.

23 N. A. A. Rahim, W. McDaniel, K. Bardon, S. Srinivasan, V. Vickerman, P. T. C. So and J. H. Moon, Adv. Mater., 2009, 21, 3492-3496.

24 J. H. Moon, W. McDaniel, P. MacLean and L. E. Hancock, Angew. Chem., Int. Ed., 2007, 46, 8223-8225.

25 P. Howes, R. Thorogate, M. Green, S. Jickells and B. Daniel, Chem. Commun., 2009, 2490-2492.

26 C. Wu, B. Bull, K. Christensen and J. McNeill, Angew. Chem., Int. Ed., 2009, 48, 2741-2745.

27 J. H. Moon, P. MacLean, W. McDaniel and L. F. Hancock, Chem. Commun., 2007, 4910-4912.

28 J. H. Moon, W. McDaniel, P. MacLean and L. E. Hancock, Angew. Chem., Int. Ed., 2007, 46, 8223-8225.

29 C. Wu, B. Bull, C. Szymanski, K. Christensen and J. McNeill, ACS Nano, 2008, 2, 2415-2423.

30 X. L. Feng, G. M. Yang, L. B. Liu, F. T. Lv, Q. Yang, S. Wang and D. B. Zhu, Adv. Mater., 2012, 24, 637-641.

31 P. Howes, M. Green, A. Bowers, D. Parker, G. Varma, M. Kallumadil, M. Hughes, A. Warley, A. Brain and R. Botnar, J. Am. Chem. Soc., 2010, 132, 9833-9842.
32 K. Li, D. Ding, D. Huo, K.-Y. Pu, N. N. P. Thao, Y. Hu, Z. Li and B. Liu, Adv. Funct. Mater., 2012, 1-9.

33 L. P. Fernando, P. K. Kandel, J. B. Yu and J. McNeill, Biomacromolecules, 2010, 11, 2675-2682.

34 X. L. Feng, F. T. Lv, L. B. Liu, H. W. Tang, C. F. Xing, Q. O. Yang and S. Wang, ACS Appl. Mater. Interfaces, 2010, 2, 2429-2435.

35 J. F. Pizzolato and L. B. Saltz, Lancet, 2003, 361, 2235-2242. 36 V. M. Herben, W. W. ten Bokkel Huinink and J. H. Beijnen, Clin. Pharmacokinet., 1996, 31, 85-102.

37 F. E. Onen-Bayram, I. Durmaz, D. Scherman, J. Herscovici and R. Cetin-Atalay, Bioorg. Med. Chem., 2012, 20, 50945102.

38 P. Skehan, R. Storeng, D. Scudiero, A. Monks, J. McMahon, D. Vistica, J. T. Warren, H. Bokesch, S. Kenney and M. R. Boyd, J. Natl. Cancer Inst., 1990, 82, 11071112.

39 V. Vichai and K. Kirtikara, Nat. Protoc., 2006, 1, 11121116.

40 Y. Shi, M. J. van Steenbergen, E. A. Teunissen, L. Novo, S. Gradmann, M. Baldus, C. F. van Nostrum and W. E. Hennink, Biomacromolecules, 2013, 14, 1826-1837.

41 M. E. Davis, Z. G. Chen and D. M. Shin, Nat. Rev. Drug Discov., 2008, 7, 771-782. 